\title{
COUMARINS OF HAPLOPAPPUS MULTIFOLIUS AND DERIVATIVE AS INHIBITORS OF LOX: EVALUATION IN-VITRO AND DOCKING STUDIES
}

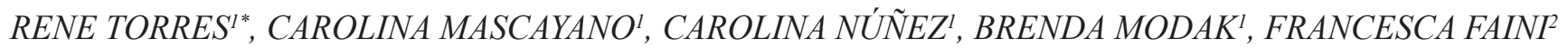 \\ ${ }^{1}$ Departamento de Ciencias del Ambiente, Facultad de Química y Biología, Universidad de Santiago de Chile. \\ ${ }^{2}$ Departamento de Química, Facultad de Ciencias, Universidad de Chile \\ (Received: July 18, 2013 - Accepted: September 4, 2013)
}

\begin{abstract}
Several natural compounds containing a coumarin moiety have been reported. They have multiple biological activities, e.g., as scavengers of reactive oxygen species (ROS) and to reduce the inflammatory processes by inhibition of enzymes like COX or LOX.

A study was made of the inhibitory capacity of seven natural coumarins and one derivative of esculetin, against soybean 15-lipoxygenase (15-sLOX). The studied coumarins showed interesting degrees of inhibition compared to quercetin, a known LOX inhibitor. Docking studies of some compounds into the binding site of 15 -sLOX and 5-hLOX were also made.
\end{abstract}

Keywords: Soybean lipoxygenase, human lipoxygenase, coumarin inhibitors of LOX, percent inhibition values, docking.

\section{INTRODUCTION}

Lipoxygenases (LOX) are a family of non-heme iron-containing enzymes that catalyse the dioxygenation of polyunsaturated fatty acids in lipids containing a cis,cis-1,4-pentadiene structure, which are classified with respect to their positional specificity of arachidonic acid oxydation and are referred to as 5-, 8-, 12- and 15-LOX.1-3

The biological properties of LOX's have been widely studied because they are involved in the biosynthesis of leukotrienes (LTs) and lipoxins (LPs) which participate in different human pathologies. For example, reticulocyte 15-lipoxygenase (15-LOX-1) has been implicated in colorectal ${ }^{4}$ and prostate cancer $^{5}$, whereas platelet 12 -lipoxygenase (12-LOX), in pancreatic ${ }^{6}$, breast ${ }^{7,8}$ and prostate cancers ${ }^{9,10}$. The most prominent isoform in LT production is 5 -LOX, which also participate in inflammation ${ }^{11}$.

Due to the great importance of simple, prenyl and oxypentenyl coumarins as anti-inflammatories, considerable efforts have been made to isolate natural compounds and to prepare synthetic derivatives. A few examples of simple natural coumarins are esculetin, daphnetin and fraxetin, recognized as inhibitors of the isoform pro-inflammatory 5-LOX and COX. Simple prenyl coumarins like osthole are moderate and selective 5-LOX inhibitors ${ }^{11}$. Finally, prenylated coumarins such as auraptene ${ }^{12}$ and umbelliprenin exhibit remarkable and potent inhibition against 15 -sLOX ${ }^{13}$.

Searching for new LOX inhibitors, we evaluated in-vitro seven coumarins previously isolated in our Laboratories from Haplopappus multifolius ${ }^{14,15}$ and one diacetyl derivative of esculetin (5), against soybean lipoxygenase (15sLOX). Some of those compounds presented better inhibitory activity than quercetin, taked as comparison compound. It is important to mention that 15 -sLOX assay may be used as preliminary study of $15-\mathrm{hLOX}$, due to the similarities between both enzymes ${ }^{16}$. Besides, some structures were docked in the active site of the crystal structure of 15-sLOX. In relation to the internal binding mode inside the 5-hLOX enzyme, the most interesting compound turned out to be 2 . The values obtained were related to the structural features present in those molecules.

\section{EXPERIMENTAL}

Melting Points were recorded on a capillary Microthermal instrument and are not corrected. Kinetics were run on a Lambda $25 \mathrm{UV} / \mathrm{Vis}$ spectrophotometer. The enzyme 15-sLOX (15-lipoxygenase soybean-P1) was purchased from Cayman Chemical.

Coumarins 1-7 were isolated from leaves of Haplopappus multifolius and their structures had been reported previously ${ }^{14,15}$. Compound $\mathbf{8}$ was prepared from $\mathbf{5}$, by an acetylation in the common way. ${ }^{1}$ NMR spectra were obtained on a Bruker Avance DR 400 spectrometer with TMS as internal standard.

\section{Percent inhibition assays}

Percent I values were obtained by a modification of a previously described method $^{17}$ using $25 \mathrm{mM}$ Hepes buffer ( $\mathrm{pH} 7.5$ ) with $0.01 \%$ Triton X-100 for 15 -s LOX and arachidonic acid as substrate $(10 \mu \mathrm{M})$. Enzyme rates were determined by monitoring the formation of hydroperoxyeicosatetraenoic acid (HPETE) at $234 \mathrm{~nm}$ on a Lambda $25 \mathrm{UV} / \mathrm{V}$ is spectrophotometer at $25 \pm 0.1^{\circ} \mathrm{C}$. The inhibitors $(1 \mathrm{mg} / \mathrm{mL}$ in DMSO) were added to the buffered substrate and the reaction was initiated by addition of the 15 -s LOX enzyme $(10 \mu \mathrm{L})$. Control rates were measured using the same volumes of DMSO and of inhibitor. Percent I was determined by measuring absorbance vs time.

\section{Docking studies}

All structures were built with the GaussianView software ${ }^{18}$. Restrained electrostatic potential (RESP) charges were obtained at the B3LYP/6-31G** level of theory employing the Gaussian 03 package $^{19}$. Docking of inhibitors into the active site of the crystal structure of 15-lipoxygenase soybean-P1 (PDB code $1 \mathrm{~N} 8 \mathrm{Q}$ ) at $2.1 \AA$ of resolution was performed with the AutoDock 4 package $^{20}$ using a Lamarckian algorithm and assuming total flexibility of the inhibitors and partial flexibility for the His residues coordinated with $\mathrm{Fe}^{3+}$ inside the binding site. The grid maps were made up of $60 \times 60 \times 60$ points, with a grid-point spacing of $0.375 \AA$. The AutoTors option was used to define the ligand torsions, and the docking results were then obtained by a ranked cluster analysis, resulting in conformations with the highest overall binding energy (most negative $-\Delta \mathrm{G}_{\text {binding }}$ value.). Finally, a docking study using human 5-lipoxygenase (PDB code: $308 \mathrm{Y}$ ) at $2.39 \AA$ resolution on derivative 2 was obtained.

\section{RESULTS AND DISCUSSION}

The structures of all the natural coumarins isolated from Haplopappus multifolius ${ }^{14,15}$, and the derivative $\mathbf{8}$, were characterized by spectroscopic methods and comparison with known compounds. The structures of the compounds are shown in Figure 1:

1 7-O-prenyl-coumarin; 2 6-hydroxy-7-[(E,E)-3',7'-dimethyl-7'-hydroxy2',5'-octodienyloxy] coumarin; 3 6-hydroxy-7-[(E,E)-3', 7'-dimethyl-5'-hydroxy-2',6'-octodienyloxy] coumarin; 4 6-hydroxy-7-prenyl coumarin (prenyletin); 5 6,7-dihydroxy (esculetin); 6 7-hydroxy coumarin (umbelliferone; $76[\beta$-D-glucopyrasyl]-7-hydroxy coumarin (esculin); 8 6,7 diacetyl-esculetin. The percent inhibition of all of them was compared with that of quercetin $\mathbf{9}$, a known LOX inhibitor ${ }^{21}$. 


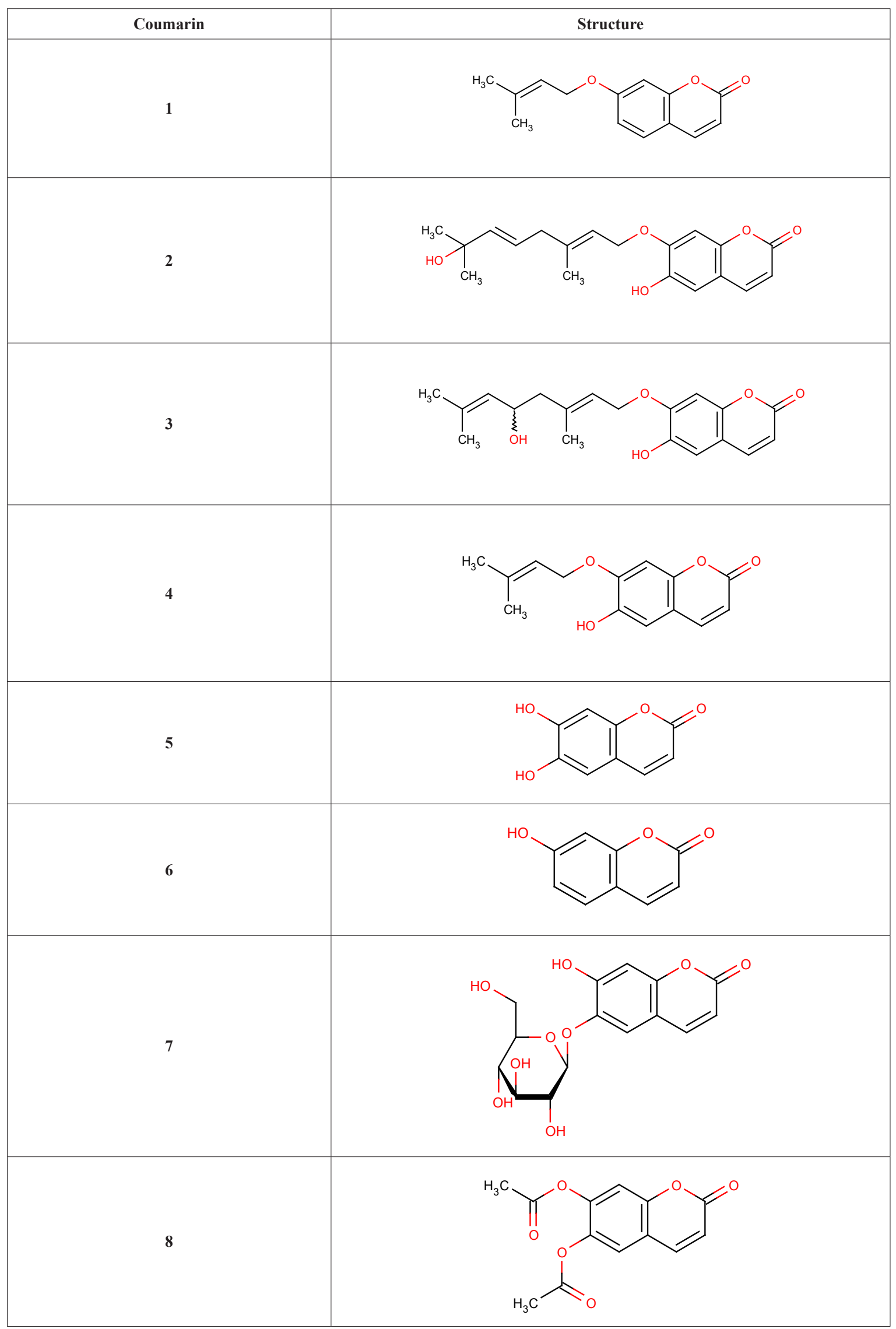


<smiles>O=c1c(O)c(-c2ccc(O)c(O)c2)oc2cc(O)cc(O)c12</smiles>

Figure 1: Structures of coumarins and derivative 1-8 and quercetin 9.

Table 1: Percent inhibition values of 15-sLOX inhibitors 1-9

\begin{tabular}{|c|c|c|}
\hline Compounds & Concentration $[\boldsymbol{\mu M}]$ & \%I \\
\hline $\mathbf{1}$ & 17.4 & $23.47( \pm 0.426)$ \\
\hline $\mathbf{2}$ & 12.7 & $34.75( \pm 2.477)$ \\
\hline $\mathbf{3}$ & 12.7 & $26.76( \pm 0.027)$ \\
\hline $\mathbf{4}$ & 20.3 & $25.78( \pm 2.109)$ \\
\hline $\mathbf{5}$ & 28.1 & $40.50( \pm 0.806)$ \\
\hline $\mathbf{6}$ & 30.8 & $37.22( \pm 1.385)$ \\
\hline $\mathbf{7}$ & 14.7 & $20.45( \pm 0.051)$ \\
\hline $\mathbf{8}$ & 19.1 & $16.06( \pm 1.244)$ \\
\hline $\mathbf{9}$ & 16.6 & $36.78( \pm 1.194)$ \\
\hline
\end{tabular}

Table 1 shows $\%$ I values. This values show the importance of concentration in relation to $\%$. The best compound was 2 with $34.75 \%$ of inhibition at a concentration of $12.7 \mu \mathrm{M} .8$ and 1 gave the worst values (16.06 and $23,47 \%$ of inhibition and 19,1 and $17.4 \mu \mathrm{M}$ of concentration, respectively). For the sake of comparison, the \% I of $\mathbf{2}$ was better than that of quercetin.

The results besides show the importance of the presence of the catechol group in the aromatic systems or a location of hydroxyl groups in the geranyl chain .Their type and location accounts clearly for the value of \% I of compound 2 compared to quercetin. Compound. 2 has well interaction of alcoholic geranyl group with non-heme iron $\left(\mathrm{Fe}^{3+}\right)$ Besides a two hydrogen bridges interaction with amino acid residues, due to a flat structure of the aromatic system, causing inhibition of the enzyme. In contrast, in quercetin this rigidity is changed into a B ring that is flexible and whose conformation does not allow good interaction in the active site, and this takes place before the quercetin can degrade to 3,4-dihydroxybenzoic acid, which according to the literature is a potent inhibitor of $15-\mathrm{sLOX}^{21-23}$.

Going over the whole table, the importance of the catechol group becomes evident, and therefore the loss of that group decreases the action against LOX. This happens when the hydroxyl groups are reduced, as seen with 7-hydroxycoumarin or in 6,7 diacetyl-esculetin $\mathbf{8}$. The simple coumarins with a terpenoid chain bonded to the $\mathrm{C}$ of benzene or to the $\mathrm{O}$ of carbon $7^{\prime}$ forming ether group, have not been studied as LOX inhibitors, and neither there are many studies on docking. In our results, O-prenylation of the phenolic hydroxyl causes a drop of the activity. Nevertheless, the inhibition increased in our new compounds $\mathbf{2}$ and $\mathbf{3}^{14,15}$, with an ether group of ten atoms chain and an aliphatic hydroxyl groups in different locations. Both coumarins are better inhibitors than quercetin. In these compounds is clear that the action of the phenolic hydroxyl group at C-6 is favored by the alcoholic hydroxyl of the geranyl chain ..

Most LOX inhibitors are antioxidants or free radical scavengers, since lipoxygenation occurs via a carbon-centered radical. In other hand, some studies suggest a relationship between LOX inhibition and the ability of the inhibitors to reduce $\mathrm{Fe}^{3+}$ in the active site ${ }^{21}$. In previous studies, the coumarins of H.multifolius showed very good antioxidant activity ${ }^{15}$. Therefore, compounds with antioxidant properties could be estimated to offer protection in rheumatic arthritis and other inflammatory diseases ${ }^{21}$ and this would be better if the coumarins have phenolic hydroxyl or cathecol groups. D o c k ing results showed that in the potent coumarin $\mathbf{2}$ the aliphatic hydroxyl is near of $\mathrm{Fe}^{3}$ and create hydrogen bridges

When carrying out docking with compounds $\mathbf{5}$ and $\mathbf{7}$ it was seen that both structures were located in the bonding site of arachidonic acid. Compound $\mathbf{5}$ was located at a distance of $3.5 \AA$ from $\mathrm{Fe}^{3+}$ (active form of the enzyme) and the bond energy was $-3.51 \mathrm{kcal} / \mathrm{mol}$. In the case of compound 7 , it was located in a very similar manner as in compound $\mathbf{5}$, but since the catechol group no longer exists, instead there is a glucose residue on $\mathrm{C}-7$ (the distance to $\mathrm{Fe}^{3+}$ is 3.3 $\AA \dot{A})$. Some decrease of the activity is because the hydroxyls are unable to join efficiently in the bonding site, and the docking energy drops to positive values of $3.3 \mathrm{kcal} / \mathrm{mol}$. Therefore, suppression of the catechol group in compound 7 is a determining factor in the low inhibition decrease

To get an idea of how the best candidate of the coumarin derivatives would behave with the key enzyme in the inflammatory processes, we performed the docking of compound $\mathbf{2}$ with 15 -sLOX and 5-hLOX. The bond energy of $\mathbf{2}$ at the bonding site with the substrate in 15 -sLOX was $-0.19 \mathrm{kcal} / \mathrm{mol}$. shown in Figure 2.

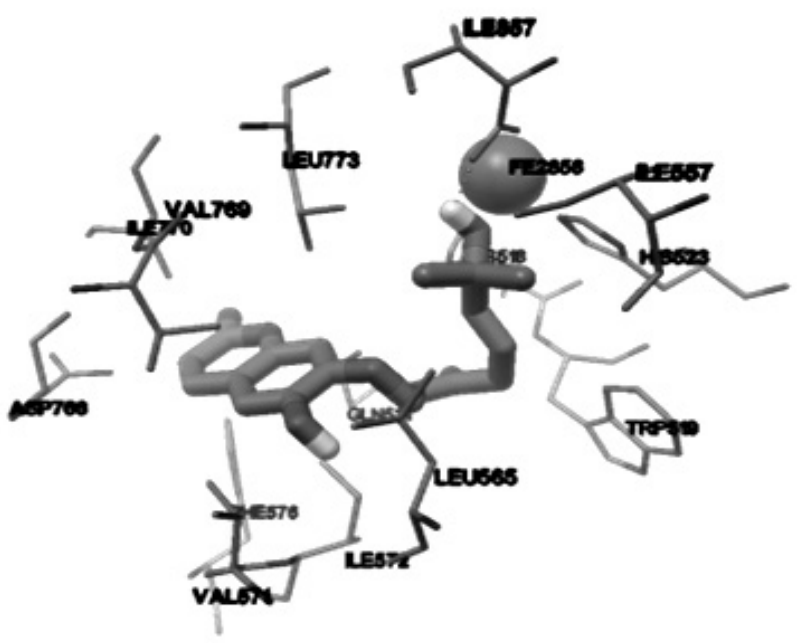

Figure 2: Docking of compound 2 with 15- sLOX

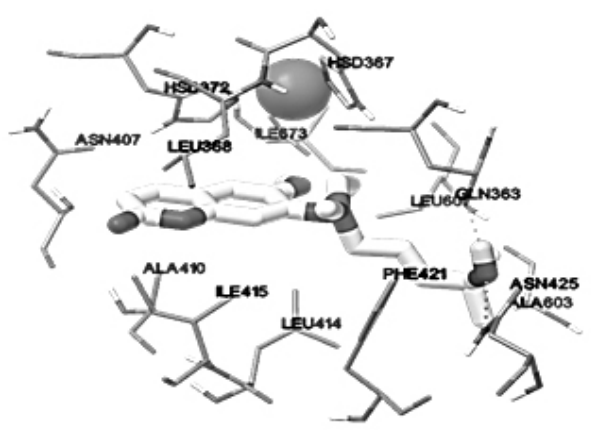

Figure 3: Docking of compound 2 with 5-hLOX

At the same time, docking of compound 2 with 5-hLOX gave a bond energy of $3.11 \mathrm{kcal} / \mathrm{mol}$, and the location of the alcoholic hydroxyl of the chain generated two hydrogen bridges with $\mathrm{Gln}^{363}$ and $\mathrm{Asn}^{425}$. Also, the phenolic hydroxyl group at position 6 was located at a distance of $3.82 \AA$ from $\mathrm{Fe}^{+3}$ (see Figure 3), and this may also be due to the fact that the size of the cavity 
of 5-LOX is greater than that of 15 -sLOX, and this would account for the variation of the interaction energy values within the active sites $^{24}$. Finally, these preliminary \% I and docking studies may suggest that compound $\mathbf{2}$ can have greater affinity for 5-hLOX and may be a good candidate as inhibitor of that enzyme. Finally, this work is in development and doing biological studies against 5-human lipoxygenase of geranyl coumarins and yours derivatives as potents anti-inflammatories.

\section{ACKNOWLEDGMENTS}

Financial support from DICYT-UdeSantiago, proyect $\mathrm{N}^{\circ} 0211141 \mathrm{TG}$ and Fondecyt $\mathrm{N}^{\circ} 1120379$ are gratefully acknowledged.

\section{REFERENCES}

1. B. Samuelson. Science 220, 568 (1983)

2. P.M. O'Byrne, E. Israel, J.M. Drazen. Ann.Inter.Med. 127, 472 (1997)

3. A.R. Brash. J.Biol.Chem. 274, 2367 (1999)

4. H. Kamitani, M. Geller, T. Eling. J. Biol. Chem. 273, 21569 (1998)

5. U. Kelavkar, W. Glasgow, T.E. Eling. Curr. Urol. Rep. 13, 207 (2002)

6. X.Z. Ding, P. Iversen, M.W. Cluck, J.A. Knezetic, T.E. Adrian. Biochem. Biophys. Res. Commun. 261, 218 (1999)

7. J.M. Connolly, D.P. Rose. Cancer Lett 132, 107 (1998)

8. R. Natarajan, J. Nadler. Front. Biosci. 3, 81 (1998)

9. D. Nied, G.G. Hillman,T. Geddes, K. Tang, C. Pierson, D.J. Grignon, K.V. Honn. Cancer Res. 58, 4047 (1998)

10. S.B. Shappell, S. Manning, W.E. Boeglin, Y.F. Guan, R.L. Roberts, L. Davis, S.J. Olson, G.S. Jack, C.S. Coffey, T.M. Wheeler, M.D. Breyer, A.R. Brash. Neoplasia 3, 287 (2001)

11. K.Fylaktakidou, D.J. Hadjipavlou-Litina, K.E. Litinas, D.N. Nicolaides. Curr.Pharmac. Des. 10, 3813 (2004)

12. M. Curini, G. Cravotto, F. Epifano, G. Giannone. Cur.Med.Chem. 13, 199 (2006)

13. M. Iranshahi, M. Ascari, A. Sakebkar, D. Hadjipavlou-Litina, Daru J.Pharm.Sci.17, 99 (2009)
14. R. Torres, F. Faini, F.delle Monache, G.delle Monache. Fitoterapia 75, 5 (2004)

15. R. Torres, F. Faini, B. Modak, F. Urbina, C. Labbé, J. Guerrero. Phytochemistry 67, 984 (2006)

16. A.T. Wecksler, N.K. García, T.R. Holman. Bioorg. Med.Chem. 16, 4589 (2009)

17. C. Kontogiorgis, D.J. Hadjipavou-Litina. J.Med. Chem. 48, 6400 (2005)

18. Gaussian 09, Revision A.1. M. J. Frisch, G. W. Trucks, H. B. Schlegel, G. E. Scuseria, M. A. Robb, J.R. Cheeseman, G. Scalmani, V. Barone, B. Mennucci, G.A. Petersson, H. Nakatsuji, M. Caricato, X. Li, H.P. Hratchian, A.F. Izmaylov, J. Bloino, G. Zheng, J.L. Sonnenberg, M. Hada, M. Ehara, K. Toyota, R. Fukuda, J. Hasegawa, M. Ishida, T. Nakajima, Y. Honda, O. Kitao, H. Nakai, T. Vreven, J. A. Montgomery, Jr., J. E. Peralta, F. Ogliaro, M. Bearpark, J. J. Heyd, E. Brothers, K. N. Kudin, V. N. Staroverov, R. Kobayashi, J. Normand, K. Raghavachari, A. Rendell, J. C. Burant, S. S. Iyengar, J. Tomasi, M. Cossi, N. Rega, J. M. Millam, M. Klene, J. E. Knox, J. B. Cross, V. Bakken, C. Adamo, J. Jaramillo, R. Gomperts, R. E. Stratmann, O. Yazyev, A. J. Austin, R.Cammi, C. Pomelli, J. W. Ochterski, R. L. Martin, K. Morokuma, V. G. Zakrzewski, G. A. Voth, P. Salvador, J. J. Dannenberg, S. Dapprich, A. D. Daniels, O. Farkas, J. B. Foresman, J. V. Ortiz, J. CiosLOXwski, and D. J. Fox, Gaussian, Inc., Wallingford CT, 2009.

19. G.M. Morris, D.S. Goodsell, R.S. Halliday, R. Huey, W.E. Hart, R.K. Belew, A.J. Olson. J. Comput. Chem. 19, 1639 (1998)

20. S.L.L. Teklu, T. Gundersen, K.E. Larsen, F. Malterud, F. Rise. Bioorg Med Chem. 13, 3127 (2005)

21. C. Mascayano, M. Caroli-Resende,Y. Rivera, V, Espinosa. J. Chil. Chem. Soc. 56, 935 (2011)

22. C. Kontogiorgis, D.J. Hadjipavou-Litina. J. Med. Chem. 48,6400 (2005)

23. Y. Vásquez-Martínez, R.V. Ohri, V. Kenyon, T.R. Holman, S. Sepúlveda. Bioorg. Med.Chem. 15, 7408 (2007)

24. S. Borngräber, M. Browner, S. Gillmor, C. Gerth, M. Anton, R. Fletterick, H Kühn. J. Biol. Chem. 274, 37345 (1999) 